\title{
An agent-based parking choice model
}

\section{Working Paper}

Author(s):

Waraich, Rashid A.; Axhausen, Kay W. (D)

Publication date:

2012

Permanent link:

https://doi.org/10.3929/ethz-a-006567764

\section{Rights / license:}

In Copyright - Non-Commercial Use Permitted

\section{Originally published in:}

Arbeitsberichte Verkehrs- und Raumplanung 
Rashid A. Waraich (corresponding author)

Institute for Transport Planning and Systems (IVT)

ETH Zurich, CH-8093 Zurich, Switzerland

phone: +41-44-633 3279

fax: +41-44-633 1057

waraich@ivt.baug.ethz.ch

Kay W. Axhausen

Institute for Transport Planning and Systems (IVT)

ETH Zurich, CH-8093 Zurich, Switzerland

phone: +41-44-633 3943

fax: +41-44-633 1057

axhausen@ivt.baug.ethz.ch

Words: $6079+(5$ Figures $)=7329$ 


\begin{abstract}
Parking choice is an essential part of individual transportation, but many travel demand and traffic simulations do not include parking. This paper proposes a simple parking model and describes how this model has been implemented into an existing agent-based traffic simulation. The parking model provides feedback to the traffic simulation so that the overall simulation can react to spatial differences in parking demand and supply. Simulation results of a scenario of the city of Zurich demonstrate that the model is able to capture key elements of parking, including parking capacity and pricing and is able to provide help for designing parking focused transport policies. The paper also discusses possible future work, such as micro-simulation of parking search for large scale scenarios.
\end{abstract}




\section{INTRODUCTION AND BACKGROUND}

Car owners often enjoy higher travel time flexibility and shorter trip durations than public transit travelers. But this flexibility comes at a high cost in terms of infrastructure including parking (1). Investment in such infrastructure is often made by public authorities. Therefore such bodies play an important role shaping travel demand by introducing new policies such as changing parking price or capacity. In order to help such authorities in their decision making, travel demand simulation models are used. However, travel demand simulation models, especially large scale ones, often lack a model for parking (2).

There is vast literature discussing the different aspects of parking and parking policies; e.g. (3) found that employer paid parking increases solo vehicle drives to work. In (4) it was reported that parking search related traffic can amount up to $20 \%$ of the total traffic at the city center. In (5) it was tried to decompose parking search into its different components, e.g. general in vehicle time, parking search time, walking time, parking cost, etc. and valuation of these components. In (6) search strategies have been described, which are often followed by the drivers. And in (7) it has been suggested that there is a significant variance in personal preferences, when it comes to value the different components of parking related time. E.g. one group of people might value search time much higher than others, while others put more importance on the walking time.

In (8) an early and extensive discussion on this topic can be found, where the need for better and practical methods for modeling parking search behavior is stressed. In order to model individual behavior of people with potentially different preferences, agent-based models seem suitable, where instead of looking at aggregated traffic flows along roads, individual people/drivers called "agents" are simulated and tracked (2). At the moment only few agent-based simulation models for parking exist, which could potentially take individual preferences into account $(9,10)$. Both these agent-based models have been successfully applied on parts of different cities containing less than 100,000 agents.

The current paper proposes a new model for parking, which focuses on parking choice and uses an agent-based model to capture individual valuation of time and differences in taste. One of the main challenges with agent-based models is to find the right level of abstraction, so that also larger scenarios are computationally feasible. The proposed parking choice algorithm has been implemented into an existing travel demand simulation framework, which is aimed at simulation of large scale scenarios with millions of agents (2). In the next section this parking choice model is presented, which is followed by a description of the implementation of the model together with simulation results.

\section{THE PARKING CHOICE MODEL}

As mentioned in the introduction the focus of the paper is parking choice. In this context, we define parking choice as the decision process of selecting a parking space from a given set of parking spaces located close to the agent's destination. In the model presented we intentionally leave out the parking search process to simplify our model. Therefore our model is aimed at static decision making rather than at decision making of an agent travelling along a link in a traffic simulation. It is envisioned that the current model will be extended and adapted to handle parking search in future. For the same reason the model is limited to parking choices encountered in everyday life where the agents already are somewhat familiar with the parking situation at the destination.

\section{Parking Types}

It was observed that often four types of parking scenarios exist, which we model as distinct parking types. The following parking types are part of the current parking model: 
- Public parking: Parking which are not reserved for any one. All agents can compete for these parking spaces.

- Private parking: These parking spaces are assigned to specific activities and buildings. E.g. parking at home or at a shop, which can only be used by residents resp. shoppers.

- Reserved parking: Parking reserved for a selected set of agents. E.g. parking reserved for disabled people.

- Preferred parking: Sometimes it is necessary that a car must park at a location with a certain characteristic. E.g. a person driving an electric vehicle might require a parking space with a power outlet for charging.

The first three parking types depend on static properties of a parking while the fourth parking type is more abstract and dynamic as it encompasses the individual situation and preferences of drivers combined with properties of the parking itself. Therefore the same parking could qualify for one agent as a preferred parking type while not for another.

\section{Utility Function}

Assume a person is given a choice set with two spaces to select from. In this case there are several parking attributes, which the person can consider for decision. Furthermore, two different people might prefer different spaces from the same choice set depending on their socio demographics, e.g. age, gender or income. In our model we assign a utility score to each parking space from a simulation agent's perspective to allow comparing different parking spaces. Such a utility score might look something like Equation (1).

$$
U_{\text {parking }}=\sum U_{\text {walking }}+U_{\text {parkingCost }}+\cdots(1)
$$

The walking distances to the destination or the parking cost are both characteristics, which have an influence on the decision of people and are as such part of the utility function. The parking cost itself can further depend on parking duration and time of day. And of course the income itself has an influence on how strong the parking cost is perceived. More factors can be added to this utility function such as security concerns of parking where the same parking could be perceived differently on a gender basis and time of day. Of course the different parts of the utility function have to be properly weighted according to the valuation of the person, which can for example stem from stated/revealed preference choice surveys.

\section{The Parking Choice Algorithm}

For each parking choice decision for a given destination, the algorithm depicted in Figure 1 is applied. The algorithm starts with all parking spaces located close to a destination. From this set of spaces first all occupied ones are removed. Then if the agent is looking for a certain type of parking (preferred parking), all spaces not fulfilling that criteria are discarded from the set. If the person is not looking for a preferred parking, all spaces are filtered out, which the person is not eligible for (e.g. reserved parking or private parking). If the parking set resulting after execution of this whole filtering process is empty, the algorithm starts again with a larger parking set by extending the distance from the destination. If the parking set contains some parking spaces, a utility score is calculated for each parking space according to a utility function as described in Equation (1) and the parking space with the highest utility score is assigned to the agent. After this assignment, the parking space is marked as occupied by the agent and is no longer available for other agents.

The presented model is hierarchical in the sense that it makes decisions on two levels: On the top level, the general set of parking spaces is defined based on the parking supply (parking occupancy, reserved/private parking available and agent's preferences). And then after the decision on the top 
level has been made, the individual valuation of the agent for different properties of the parking space, e.g. price or walking distance are considered using the utility function.

It is important that the initial parking set is large enough, so that a tradeoff can be made by the agent based on the utility function. For example if the set is chosen too small and only costly parking spaces would be located close to the destination, the agent would not be able to make a tradeoff with regards to the walking distance and be unable to consider parking spaces further away. On the other side, if the parking set is chosen too large, where in the extreme case all parking spaces in the study area are selected, this would become a performance issue.

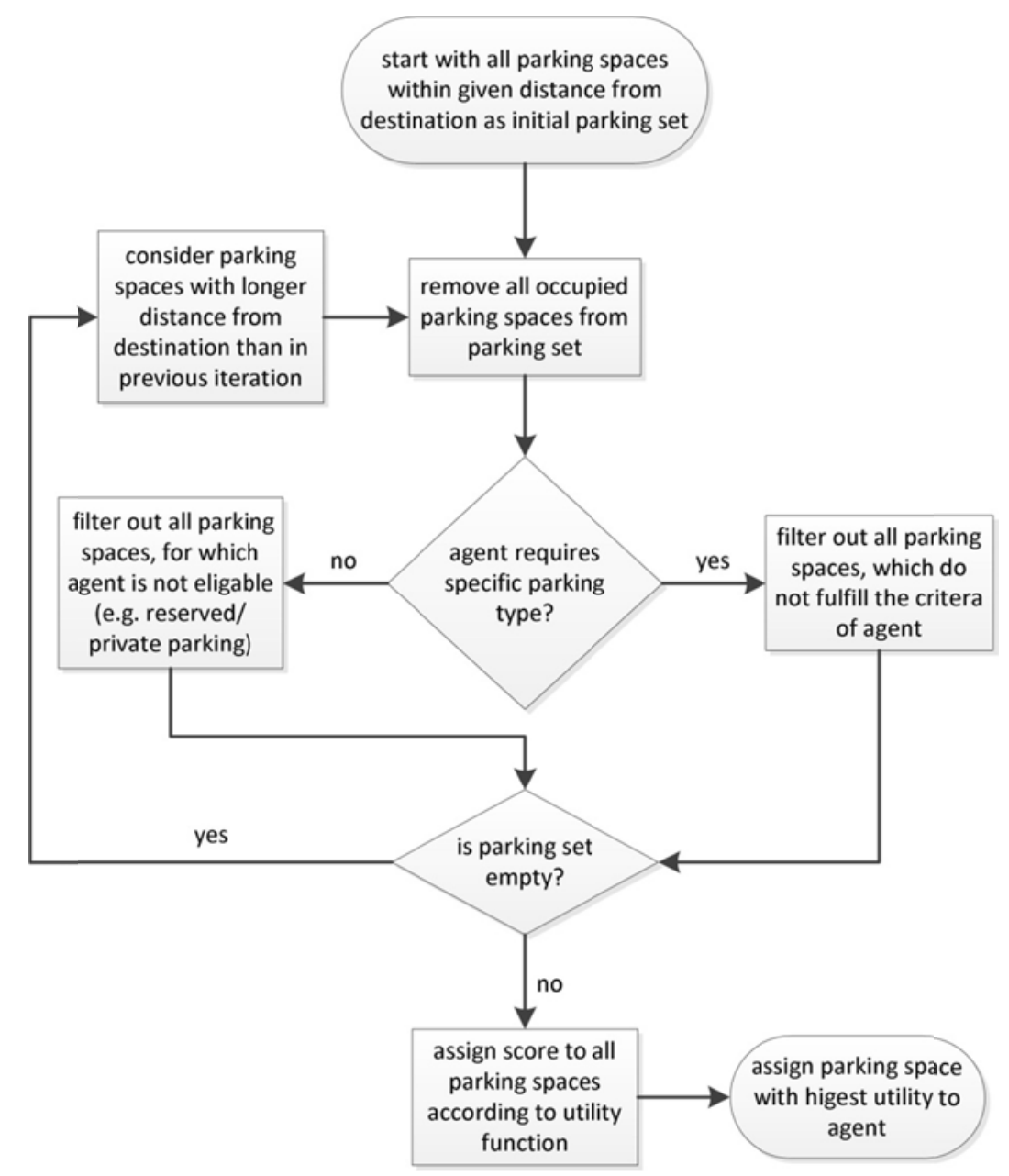

\section{Figure 1: Parking Choice Algorithm}

\section{External Feedback}

Although the utility score presented in Equation (1) is only used inside the parking choice algorithm, it can also be made available to the travel demand simulation framework surrounding the parking choice algorithm. This would give the overall simulation framework the possibility to react according to such a feedback from the parking choice. E.g. if in an area the parking supply is lower than demand, some people might have to walk long distances between parking and destination. If the utility score information for each selected parking space by an agent is given to the traffic simulation, it can perform appropriate steps to react to this situation, e.g. by allowing the agent to change travel time, location or mode.

\section{Leaving out Decisions made at Road Intersections}


As stated earlier, the model does not consider parking search. It seems parking choice decisions are a combination of acquired knowledge of the parking situation over time (11) and decisions made as driving along roads and intersections when searching for a parking space and thereby taking the actual traffic flows and occupancy of parking into account. The parking choice algorithm presented performs a partial combination of both approaches when it evaluates parking spaces according to the agent's utility function and the actual parking occupancies encountered in the simulation. In this way the proposed algorithm always finds the best suitable parking for the agent for the given destination. Although in reality people might not always make such optimal decisions, the simulation runs shown in this paper suggest that the model is able to capture a significant portion of ellements which matter most for parking choice.

In the next two sections, we describe how this simple model can be incorporated into an existing traffic simulation and applied to a larger scenario.

\section{IMPLEMENTATION}

In order to test our parking model, we have extended MATSim (2), which is an agent-based traffic simulation framework aimed at large-scale simulations, containing up to several million agents on high resolution networks $(12,13)$.

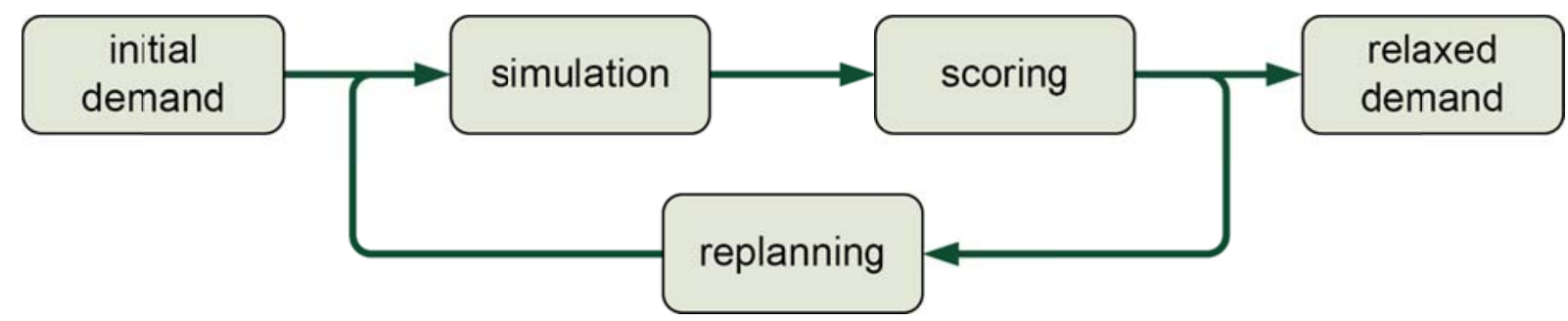

Figure 2: Co-evolutionary simulation process of MATSim, Source: (14)

Figure 2 shows the MATSim simulation process: Each agent in MATSim has a daily plan of trips and activities, such as going to work, school or shopping. The initial daily plans of agents are provided in the initial demand together with supply models, e.g. street network and building facilities. The plans of all agents are executed by a micro-simulation, resulting in traffic flow along network links, which can cause traffic congestion. The execution of these plans is then sicored and assigned a utility. For example a person with lower travel time has a higher utility than one, which has a longer travel time because of traffic congestion. Furthermore working (earning money) and other activities increase the utility. The goal of each agent is to maximize the utility of its daily plan by replanning its day, which is based on a co-evolutionary algorithm (15). The daily plans are evaluated, and "bad" daily plans (plans with low performance, respectively low utility) are deleted, which corresponds to survival of the fittest in co-evolutionary algorithms. Thereafter new plans are generated based on the previous set of plans. The replanning algorithm can use several degrees of freedom, such as changing routes, working time, travel mode or location choice of agents. The execution of all plans, its scoring and replanning is called an iteration. The simulation is an iterative process, which approaches a point of rest corresponding to a user equilibrium, called relaxed demand. More details about the conceptual framework and the optimization process of the MATSim toolkit can be found in (2).

Till now MATSim has a too simplistic parking model. It assumes that agents drive directly to the each activity location and finds a parking space there without delay. There are no constraints regarding parking supply and no notion of parking cost. In the following it is described how the presented model has been integrated into the evolutionary algorithm of MATSim, so that parking availability, price and other factors can have an influence on the overall decision making of the agent. 


\section{Utility Function}

As mentioned in the last section, the parking choice utility can be used to give feedback to the traffic simulation. The utility function in MATSim looks like Equation (2), which has been extended by adding the utility term for parking as already shown in Equation (1).

$$
U_{\text {plan }}=\sum U_{\text {travelTime }}+U_{\text {travelCost }}+U_{\text {performActivity }} \cdots+\sum \boldsymbol{U}_{\text {parking }}
$$

The utility score function of walking to/from the parking, which is an important part of the overall parking utility is defined in Equation (3). If the walking distance $x$ between the parking and destination gets longer than a threshold $\vartheta$, the marginal disutility will get higher, resulting in the parking getting increasingly uninteresting for an agent. Such a distinction is proposed, as utilities for longer distances than $\vartheta$ should be seen as a non-desirable walking distance and this information should signal to the evolutionary algorithm in MATSim that probably something is suboptimal with the given plan so that the plan should preferably be changed.

$$
\begin{aligned}
& U_{\text {walking }}(x)=\left\{\begin{array}{r}
\alpha \cdot x, x<\vartheta \\
\alpha \cdot x+\beta \cdot(x-\vartheta), x \geq \vartheta
\end{array}\right. \\
& \text { with } \alpha, \beta<0 ; \alpha \gg \beta
\end{aligned}
$$

The utility for parking cost has been modeled simple at the moment with a linear relationship with income: It is calculated as the parking cost (adjusted to the utility of performing activities) divided by the income of the agent. As in the simulated scenario in the next section the income for the agents is not known this simple utility function for parking cost seems adequate for the moment. But this will be changed in future to consider non-linear effects in valuation of parking cost with respect to agent's income for the given scenario (see for example $(16,17)$ ).

\section{Extending MATSim}

The simulation of the parking choice algorithm presented is implemented into MATSim such that it is able to run at the same time/in parallel to the MATSim traffic simulation. This saves time, which is important for large-scale simulations. The information related to the utility scores which have been assigned to agents for the selected parking are also forwarded to the MATSim simulation so that they are added to the overall score of each agent.

For the moment it was decided not to change the micro-simulation of MATSim, but rather to add the parking choice as a separate module to it. Therefore a couple of post-processing changes to the agent's plan are necessary, so that the simulation output is consistent with the rest of MATSim (see Figure 3): In order to reflect the parking choice decision in the agent's plan, new walking legs are introduced based on the walking time for each parking choice made. Furthermore short activities for egress time and boarding time are added to the plan. For the simulations in the next section we used fixed time intervals of 30 seconds for egress and boarding of the vehicle. Although the parking search time inside both garage parking and for street parking is not part of the model yet, the search time could be modeled based on existing models (see (18) for an example). As the time available for performing activities at the destination is reduced due to parking related activities, also the utility function in MATSim has to be adapted, to reflect this change. As a final step, the adapted plans should be simulated again in MATSim for a couple of iterations, with only route choice turned on, so that the parking related trips are part of the final result.

The parking choice algorithm in MATSim has been implemented in a quite generic way, so that it can be used for different applications. There is a default parking choice strategy implemented as 
described in the description of the algorithm. But if the agent requires a different parking space for certain situations, he can do so. E.g. in the city of Zurich it is possible to buy a monthly permit for local public on-street parking. If we have information about the ownership of such parking permit in our model, we can say that agents owning such parking permit prefer to park on the street, instead of using parking garages.

without parking choice

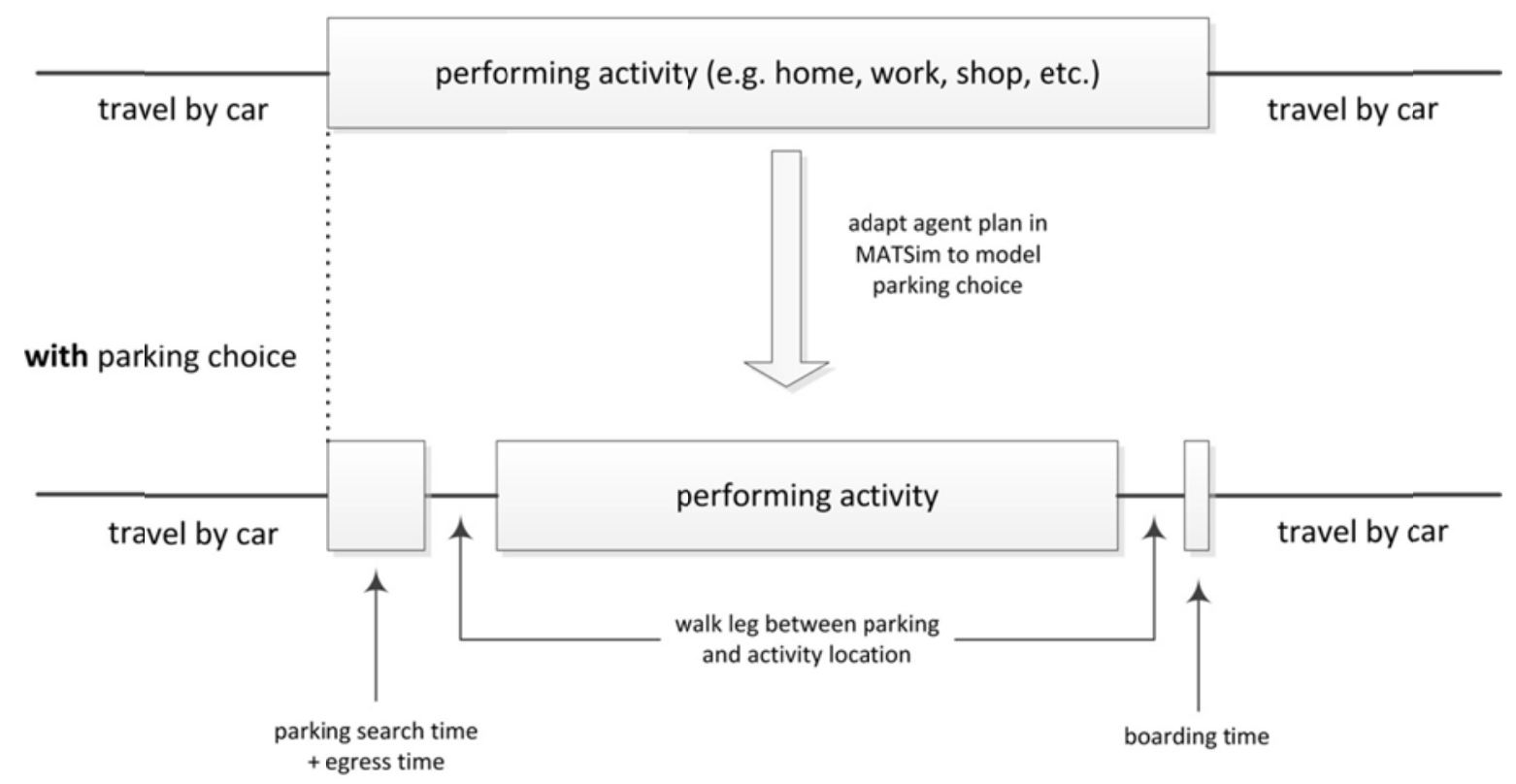

Figure 3: Changing plans to incorporate parking activities

\section{SIMULATIONS}

An existing national scenario of Switzerland for MATSim (12) was calibrated for the area around the city of Zurich and then recalibrated after adding the parking model. The calibration without parking was done based on the mode shares, as described in (12), whereas the calibration of the scenario with parking is described later in its own subsection.

The simulation scenario consists of all agents residing within a $30 \mathrm{~km}$ circle around a central place in Zurich. Additionally to these agents, also such agents residing outside the study area, which enter the study area at some time during the day, are included in the simulation. The network used for this simulation is a high resolution navigation network containing around one million links. For the initial tests presented here instead of simulating a $100 \%$ scenario, smaller population samples $(10 \%$ and 1\%) population scenario with around 180'000 resp. 18'000 agents were used. Such a population sampling is a common practice where the network link flow capacities are adapted to match the population sample size. Although a sampling as low as $1 \%$ may lead to artifacts especially due to the scaling of the network links, for these initial test experiments such loss in quality is not deemed critical. Naturally also the parking capacities were scaled accordingly.

The possible transportation modes available in the simulation were car, public transport, bike and walk, where only cars were physically simulated along the roads. The travel times of the other modes were based on simpler models, such as average speed for bike and walk and fixed travel time matrices for public transport. The agents could change mode, departure time, activity duration and route. 50 iterations were performed for each simulation as in the original calibration. The traffic count comparisons of the calibrated model were comparable to previous ones as reported in (12). 


\section{Parking Infrastructure Supply Model}

Several datasets were used to model the parking supply in the city of Zurich. In order to reduce the computation time and memory consumption, on-street parking (ca. 50’000 spaces) were clustered together to form new parking facilities with parking capacity assigned to them. This resulted in parking facilities with an average of ca. 6 parking per facility. For the over 100 parking garages containing more than 15'000 parking, no such clustering is performed. The modeling of the private parking (over 200'000 spaces) was more challenging, as they needed to be assigned to activities in buildings. Several approaches were tried before it was found that it would be best to distribute the private parking proportionally to the activity capacities in the buildings, which are located close to them. Parking supply data outside the city of Zurich is only sparsely available. For the simulations conducted it is assumed that the parking supply outside of the city is unlimited. Although this is not realistic, still this assumption seems no worse than the original parking model assumption in MATSim, which had no parking constraints at all. But nevertheless a parking model for outside the city of Zurich is work in progress (see future work). The pricing at the paid parking was modeled also in a simplified manner: At all garage parking the price was set to 1.50CHF/h (Swiss francs per hour, US\$ 1.90 at July 2011 exchange rates). The price at all on-street parking in central Zurich was set to 2.00CHF/h (all on-street parking within $1 \mathrm{~km}$ radius around "Lindenhof"). For the threshold $\vartheta$ after which the marginal disutility for walking increases, a value of $350 \mathrm{~m}$ is chosen. This distance is consistent with walking distances mentioned in previous literature, e.g. 350m in (9) and 300m in (10) were reported as distances, within which the majority of the parking related walking stages lie.

\section{Calibration}

For calibration of the parking demand, online data about the occupancy of the parking garages was collected from a website (19) on a minute by minute basis together with the parking garage capacities. As there were some inconsistencies between the parking capacity information available on the website and the data received from the city authorities, only such parking garages were compared where the parking capacities from both sources matched each other. Parking occupancy data from 25 such parking garages was chosen randomly for the calibration. As in the scenario an "average weekday/Wednesday" is simulated, parking occupancy data for the whole day of Wednesday, 27th April 2011 was used for the comparisons.

Due to the uncertain allocation of private parking to buildings/activities, the share of private parking in the model needed to be scaled to match the scenario. Therefore, the total share of private parking in the scenario was adjusted during the calibration until, the occupancy at the parking garages in the simulation matched roughly the numbers measured in the real world.

Figure 4 visualizes the outcome of this procedure, where both the sum of real parking occupancy counts and the simulated parking counts at the 25 parking after the initial parking iteration (it.0) and the last iteration (it.50) are shown. As this is a $10 \%$ scenario, the numbers are scaled down, so that in reality a peak occupancy of around 6000 vehicles at the selected parking garages was measured for the day. The general shape of the occupancy at the garage parking comparison looks good, but there are too low volumes reported by the simulation for overnight parking, which indicates that some demand is missing in the scenario, most likely residents parking second and third cars, which is not properly captured in the car ownership model we used to describe the agent population.

The simulated parking related walking distance distribution within the city has the expected asymptotic shape. Around $2 / 3$ of the agents are parking within $100 \mathrm{~m}$ from the destination, around 95\% within 450m. In (10) parking walking distance for another European city is reported, with a higher parking related walking distance: $2 / 3$ of the people park within $300 \mathrm{~m}$ from the destination. This 
could possibly indicate that there are too many private parking spaces availablle, but this has to be verified in the future, e.g. with survey data from Zurich. In the simulation $1 \%$ of the agents walked more than $900 \mathrm{~m}$. These long walking distances also require special attention, as they could indicate possible errors in the demand or supply model.

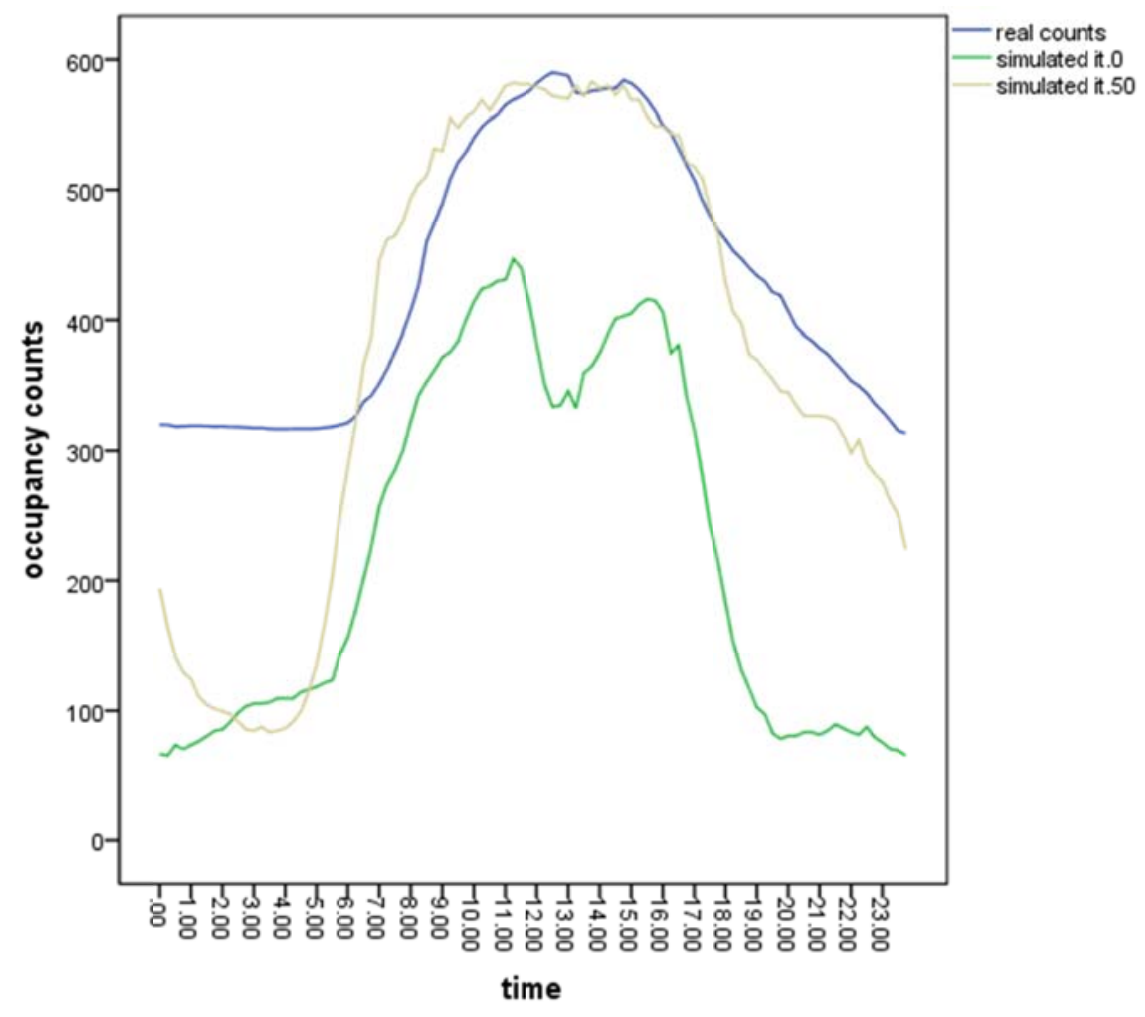

\section{Figure 4: Calibration of Counts}

\section{Sample Parking Policy}

Several experiments were performed during calibration that showed that the model is sensitive to the different parameters, including parking type, walking distance and parking cost. In the following an example is given, how the presented parking model could be utilized to design and test a new parking policy.

Assume that someone came up with the idea, that one could reduce peak traffic volumes at certain links by reducing parking supply in the city of Zurich. One example how such a policy measure could be designed and tested with the presented parking choice model is demonstrated here:

1. To simplify the task we only focus on the evening peak here. First the top $10 \%$ links with the highest traffic volume during peak hour are identified.

2. Afterwards we identify all agents in the simulation, which travel over these high volume links during peak hour.

3. One idea to reduce the traffic on those high volume links could be to identify where the agents selected in the previous step perform activities and reduce parking supply in those areas. For doing so the location of the previous and next activity related to the trip leading over the high volume link during peak hour is identified for the selected agents. If any of those activities is located inside the city, we mark that activity location for consideration in the next step.

4. In this step such areas are identified, where a lot of agents who contribute to volume on the identified links during peak hour are performing activities. For doing so clusters of the activity 
locations identified in the previous step are formed and the clusters with the highest number of activities are chosen.

5. In order to reduce parking supply, public parking is reduced in the selected areas/clusters.

\section{Experiment}

For this experiment a $1 \%$ population sample was used to execute the simulations faster. The evening peak hours were defined as 16:00 to 19:00. The cluster size was chosen as $500 \mathrm{~m}$ and the top 4 clusters with cluster sizes ranging between 22 and 38 were selected (corresponding to ca. 2200 to 3800 vehicles per cluster in a $100 \%$ population sample).

In order to demonstrate the potential of the policy measure, two experiments were performed. In one experiment $30 \%$ of the public parking in the identified clusters were removed whereas in the second experiment all public parking spaces from the identified areas were removed.

Result

In Figure 5 the volume change for the top $10 \%$ volume links is shown after applying the measure. One can see that the highest reduction in traffic volumes happens during evening peak hour at the selected links. As the results show, at least some agents decided to shift their mode. As MATSim is an iterative process, where agents always try to find faster links for travelling, it is not surprising that the volumes at the selected links also change during the rest of the day. But this also raises the question, if the change in volumes is just random due to the iterative nature of MATSim. Although it seems not very probable, that the high reduction in traffic volumes is just random, more runs need to be performed to find out, how much of this volume change is just due to random change of plans of agents in MATSim.

Although this experiment is conducted by looking at high volume links, one might also look in the future at high congestion links instead, meaning links with much lower average speed than maximum speed allowed. It could be interesting to see, how much influence such a measure would have on the travel time in the system in general and how much the average speed at congested links could possibly increase.

One replanning dimension, which is not available to the agents in the simulations conducted, is location choice. E.g. due to the parking reduction, people who were going to shop in one location might go shopping somewhere else. This possibility might be added to future runs, as described in (20).

Real world policies are often based on political discussions, feedback from residents and shop owners. But also in this setting the reduction in parking can be based both on output from the parking choice simulation and the interests of the general public. In this way the presented model could be used to find out what possibly could happen due to the introduction of the new measure. 


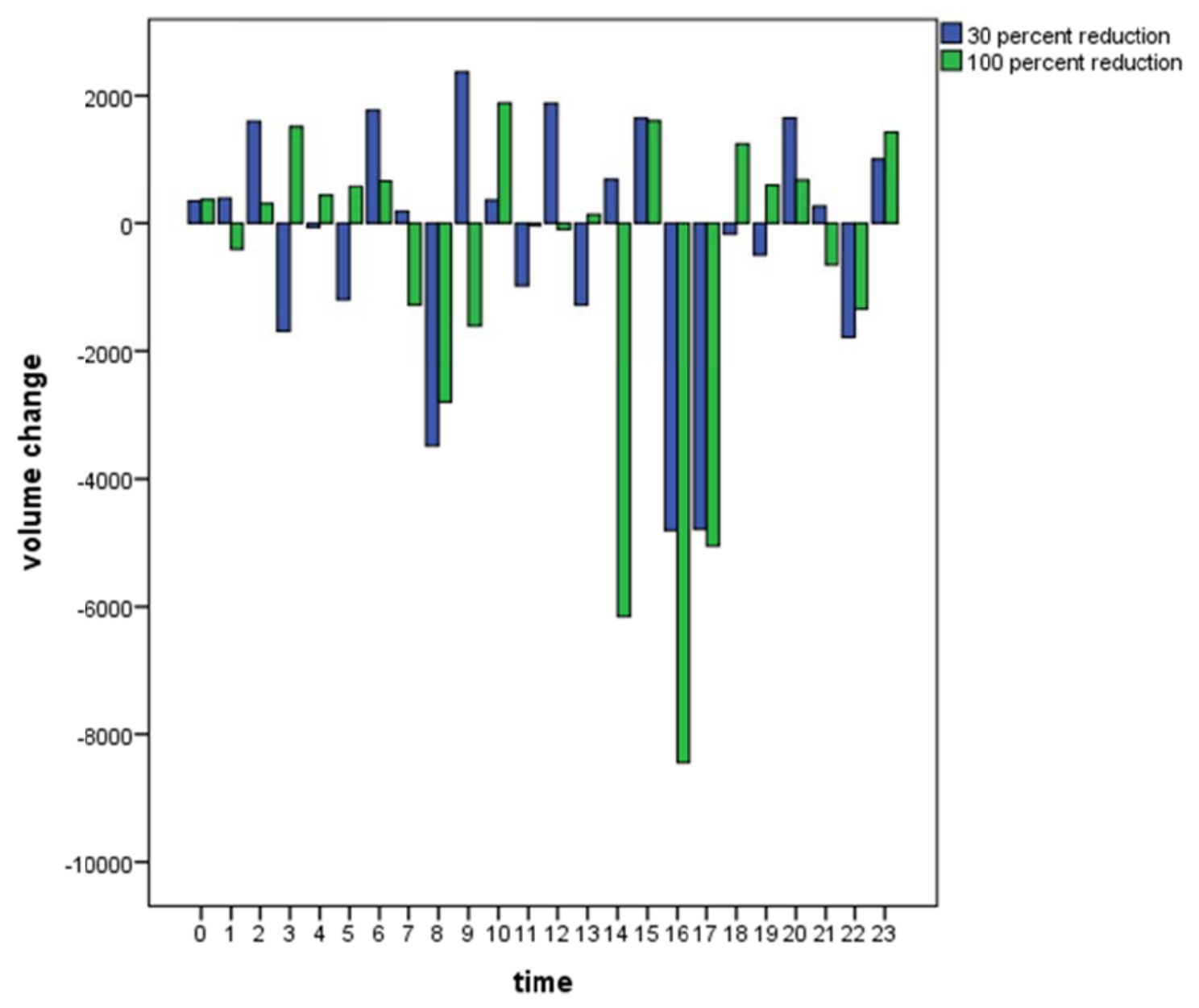

Figure 5: Changes in traffic volumes after reducing parking supply in selected areas of Zürich

\section{DISCUSSION AND FUTURE WORK}

\section{Improve the Parking Model for Zurich}

The presented scenario for Zurich is planned to be improved in several ways.

- A new Zurich Scenario (21) has just recently been calibrated for MATSim containing several improvements such as addition of freight transport and a detailed micro-simulation of public transit. This new scenario could be tested with parking choice in the future to compare how the different parking indicators, e.g. parking occupancy changes.

- The parking supply data outside the city of Zurich also needs to be improved. Some data for this can come from national surveys and others from township or imputation models.

- The parking supply model inside Zurich can be improved in several ways: The current pricing is far too simplistic to reflect the spatial differences in price. Actual prices are available for the garage parking and metered street parking which can both be incorporated in the future. Furthermore a division of the street parking into several categories could be done, as some data on this is also available.

- At the moment we only look at the sum of occupancies at the garage parking for calibration. But the real occupancies at the public garages show, that there are huge differences in the shape of the occupancy curves at different garages over the day. In the future we could also take such spatial differences into account. To improve calibration and vallidation of the model, 
additional data needs to be collected such as the occupancy log at the metered on-street parking. Such data should be available for metered street parking from the city authorities. Furthermore also data on parking related walking distances would need to be included in future surveys from urban areas, and Swiss cities in particular.

\section{Improving Parking Choice in MATSim}

- Although the model presented is agent-based, in the presented scenario the attitude of all agents towards parking was the same. This should change in the future starting with the addition of income data to both the Zurich scenario and also an improved model for the parking cost utility. Also additional information from city authorities, such as where the people live who have paid for a monthly public street parking permit needs to be integrated. Furthermore people's attitude towards illegal parking could become part of the parking utility function, which could for example also take the level of law enforcement into account. A model for the disposition of people towards illegal parking could be based on real data from Zurich.

- In (22) the effect of parking information services on traveler's behavior is discussed and demonstrated that there are demographic differences in the usage of such information. In (23) it is also discussed that not all parking garages and on-street spaces are known to people and therefore the selection of a parking lot is based on a subset of all existing/available parking. In the current paper this has not been looked at, but such an extension could be possible. For example a simple model could define randomly a fixed set of parking from the surrounding of a destination for each agent, which is unknown to that agent.

\section{Adding Parking Search}

- Many of the ideas presented in the parking choice algorithm, can be reused also in the context of parking search. It is planned that the current model should be extended/adapted in future to include also parking search, so that a high demand for car travel at destination could be reflected also in terms of increased parking search related traffic in that area as often reported, e.g. (4).

\section{CONCLUSIONS}

In this paper a new parking choice model is proposed, implemented into an existing travel demand simulation and initial simulations with over 100 '000 agents are presented. The results show that the parking choice model can help to improve the existing traffic model, so that replanning of the agents can take parking occupancy, walking distance and price preferences into account. Furthermore the presented model also forms a foundation of additional work, which the authors are pursuing in (14), where the potential future electricity demand by electric vehicles is modeled. For such an application, the presented parking choice algorithm provides the parking choice hierarchy and parking types, which are necessary as a generic parking model is not enough. The presented parking choice model is just the beginning of a series of improvements for MATSim and extensions and adaptions of the model are planned so that it can give guidance for a large range of policy makers.

\section{ACKNOWLEDGEMENT}

We would like to thank our colleagues Mr. Andreas Horni, Dr. Marcel Rieser and Mr. Basil Vitins for discussions related to the simulations. Thanks also to Mr. Felix Bösch and Mr. Michael Schirmer for providing us data for the public and private parking spaces of the city of Zurich.

\section{REFERENCES}


[1] Shoup, D. (2005) The High Cost of Free Parking. Chicago, IL: Planner's Press.

[2] MATSim-T (2011) Multi Agent Transportation Simulation Toolkit, webpage, http://www.matsim.org, last time accessed July 2011.

[3] Willson, R.W. and D.C. Shoup (1990) Parking Subsidies and Travel Choice: Assessing the Evidence, Transportation 11:141-157.

[4] Huber, M.J. (1962) 'Street travel related to local parking', Highway Research Record, 41, Washington.

[5] Axhausen, K.W. und J.W. Polak (1991) Choice of parking: Stated preference approach, Transportation, 18 (1) 59-81.

[6] Axhausen, K.W. (1989) 'Ortskenntnis und Parkplatzwahlverhalten', report to the Deutsche Forschungsgemeinschaft, Institut für Verkehrswesen, Universität (TH) Karlsruhe, Karlsruhe.

[7] Hess, S. and Polak, J.W. (2004) An analysis of parking behaviour using discrete choice models calibrated on SP datasets, ERSA conference papers, European Regional Science Association, 2004.

[8] Polak J.W. and Axhausen K.W. (1990) Parking Search Behavior: A Review of Current Research and Future Prospects. Working Paper 540, Transport Studies Unit, University of Oxford, England, 1990.

[9] Benenson I., K.Martens, and S.Birfir (2008). PARKAGENT: An agent-based model of parking in the city. Computers, Environments and Urban systems, 32, 431-439

[10] Spitaels, K., Maerivoet, S., De Ceuster, G., Nijs, G., Clette, V., Lannoy, P., Dieussaert, K., Aerts, K., Steenberghen, T. (2009), Optimising Price and Location of Parking in Cities under a Sustainability Constraint (SUSTAPARK), Final Report. Brussels: Belgian Science Policy 2009 - 104 p. (Research Programme Science for a Sustainable Development).

[11] Pinto, A. C., \& Baddeley, A. D. (1991). Where did you park your car? Analysis of a naturalistic long-term recency effect. European Journal of Cognitive Psychology, 3, 297-313.

[12] Meister, K., M. Balmer, F. Ciari, A. Horni, M. Rieser, R.A. Waraich and K.W. Axhausen (2010) Large-scale agent-based travel demand optimization applied to Switzerland, including mode choice, paper presented at the 12th World Conference on Transportation Research, Lisbon, July 2010.

[13] Waraich, R. A., D. Charypar, M. Balmer and K.W. Axhausen (2009) Performance improvements for large scale traffic simulation in MATSim, paper presented at the $9^{\text {th }}$ Swiss Transport Research Conference, Ascona, September 2009.

[14] Waraich, R.A., M.D. Galus, C. Dobler, M. Balmer, G. Andersson and K.W. Axhausen (2009) Plug-in Hybrid Electric Vehicles and Smart Grid: Investigations Based on a MicroSimulation, paper presented at the $12^{\text {th }}$ International Conference on Travel Behaviour Research (IATBR), Jaipur, December 2009.

[15] Holland, J. H. (ed.) (1992) Adaptation in Natural and Artificial Systems: An Introductory Analysis with Applications to Biology, Control, and Artificial Intelligence, MIT Press, Cambridge.

[16] Ciari, F. and K.W. Axhausen (2011) Choosing carpooling or car sharing as a mode: Swiss stated choice experiments, Arbeitsberichte Verkehrs- und Raumplanung, 694, IVT, ETH, Zürich.

[17] Weis, C., M. Vrtic, P. Widmer and K.W. Axhausen (2011) Influence of Parking on Location and Mode Choice: A Stated Choice Survey, Arbeitsberichte Verkehrs- und Raumplanung, 684, IVT, ETH Zürich, Zürich. 
[18] Axhausen, K.W., J.W. Polak, M. Boltze and J. Puzicha (1994) Effectiveness of the parking guidance system in Frankfurt/Main, Traffic Engineering and Control, 35 (5) 304-309.

[19] Parkleitsystem Stadt Zürich, www.pls-zh.ch, last time accessed July 2011.

[20] Horni, A., D.M. Scott, M. Balmer and K.W. Axhausen (2009) Location Choice Modeling for Shopping and Leisure Activities with MATSim: Utility Function Extension and Validation Results, Arbeitsberichte Verkehrs- und Raumplanung, 574, Institute for transport planning and system (IVT), ETH Zurich, Zurich.

[21] Horni, Vitins and Axhausen (2011) The Zurich Scenario: A Technical Overview, Arbeitsberichte Verkehrs- und Raumplanung, 687, IVT, ETH Zürich, Zürich.

[22] Khattak, A. and J. Polak. Effect of parking information on travelers' knowledge and behavior. Transportation, Vol. 20, 1993, pp. 373-393.

[23] Bovy, P. H. L., and E. Stern. Route Choice: Wayfinding in Transport Networks. Kluwer Academic Publishers, Dordrecht, Netherlands, 1990. 